\title{
A Lyapunov Function for Vector Control Drives in Induction Machines
}

\author{
Reza Sangrody \\ Department of Electrical Engineering \\ Firoozkooh Branch, Islamic Azad University \\ Firoozkooh, Iran \\ Rezaa_sangrody@yahoo.com
}

\author{
Seyed Mohammad Shariatmadar \\ Department of Electrical Engineering \\ Naragh Branch, Islamic Azad University \\ Naragh, Iran \\ Shariatmadar@iau-naragh.ac.ir
}

\begin{abstract}
In this paper a useful Lyapunov function for vector control of induction machines is introduced. To do this, some beneficial theorems are reviewed and by applying these theorems and state equations to a vector control drive, its candidate Lyapunov function is achieved. Range of set points such as reference speed, reference flux linkage values and speed controller gain is obtained for such a drive and therefore these values can be set offline to avoid unstable behavior. The simulated and experimental results are given in the last section of the paper to show the efficacy of the given Lyapunov function.
\end{abstract}

Keywords-Lyapunov function; stable Area; vector control drives

\section{INTRODUCTION}

A linear system shows stable, unstable, or oscillated responses; however, in a nonlinear system other kinds of behaviors such as bifurcated, chaotic and sub harmonic may occur. Electric machines are highly nonlinear systems because they have mutual dynamics. In addition, electric drives, or other controller types, are implemented in electric machines to control their speed, torque and thus also result to a nonlinear behavior. These time responses are not acceptable except the stable cases from an application point of view. It is obvious that these nonlinear behaviors cause fluctuation in electromagnetic torque, speed of the rotor, current and voltage components, flux linkages, etc. Strange time responses in electric machines drives such as induction machines, synchronous reluctance machines, permanent magnet synchronous machines, DC machines, brushless DC machines, etc. has been reported in several paper [1-7].

Nowadays vector control drives of induction machines are more suitable for a variety of applications such as trains, conveyer belts because of their dynamical behavior as well as for having a tough structure and cheap price. As mentioned, these drives may represent stable, unstable and chaotic responses. There are some researches that show the bifurcated and chaotic response of these drives caused by different reasons like inverter malfunction $[8,9]$, error in parameters' values like rotor and stator resistances [10-13] or even because of an inherent nonlinearity of the system [14].

Some researchers used Poincare map to study these behaviors. The Poincare map is a powerful method to investigate the strange behaviors such as chaotic and bifurcated ones $[14,15]$. This map is useful for power electronic systems such as DC-DC choppers. However, it is not useful and applicable enough to analyze the stability of other systems such as induction machine drives which are the case study of this paper. One of the most powerful methods to study the global stability of nonlinear systems is the Lyapunov method. Using a Lyapunov function is the main core of the method. Finding these functions for nonlinear systems is difficult. Suitable theorems to evaluate the stability of nonlinear systems are needed [14]. In this paper these theorems are used to achieve a useful Lyapunov function for vector control drives in induction machines.

\section{CANDIDATE LYAPUNOV FUNCTION FOR TRANSFORMED DYNAMICS}

Finding the Lyapunov function for a nonlinear system is very important, because stability analysis or controller design such as sliding mode controller, adaptive control, etc. are based on this function. According to the Lyapunov theory there is a nonlinear system such as:

$$
\dot{X}=F(X) \quad X \in R^{n}
$$

If a function such as $V: R^{n} \rightarrow R$ with the following conditions exists then the origin $(X=0)$ is a stable equilibrium state for this system:

$$
\begin{gathered}
V(X)>0 \\
\dot{V}(X)<0 \\
\|X\| \rightarrow \infty ; V(X) \rightarrow \infty \\
V(0)=0, \dot{V}(0)=0
\end{gathered}
$$

The shortcoming of this theorem is that there is not a unique method to obtain a Lyapunov function. Sometimes this theorem is named Lyapunov direct method. There is another theorem based on linearized dynamical equations of a nonlinear system. It talks about local stability conditions for the equilibrium states of a system. This method is called indirect Lyapunov method in nonlinear system theory. 
In [14], it was shown that if there exists a Lyapunov function like $V(X)$ for nonlinear system such as (1), then what can be concluded about the stability of a system such as:

$$
\dot{X}=H^{-1} F(X)
$$

This system is a transformed system and two theories are introduced in [16] to achieve its Lyapunov function. The origin will be stable equilibrium point for this system if there exists a positive function $g(X)$ that satisfies the following conditions.

$$
\int g(X)\left(\nabla\left(V^{2}(X)\right)\right)^{T} H d x>0
$$

And $g(X)$ will exist if the following matrix be symmetric:

$$
\left(\begin{array}{l}
\left(\frac{\partial \nabla\left(V^{2}(X)\right)}{\partial x_{1}}+\frac{\partial \ln (g(X))}{\partial x_{1}} \nabla\left(V^{2}(X)\right)\right)^{T} \\
\left(\frac{\partial \nabla\left(V^{2}(X)\right)}{\partial x_{2}}+\frac{\partial \ln (g(X))}{\partial x_{2}} \nabla\left(V^{2}(X)\right)\right)^{T} \\
\vdots \\
\left(\frac{\partial \nabla\left(V^{2}(X)\right)}{\partial x_{n}}+\frac{\partial \ln (g(X))}{\partial x_{n}} \nabla\left(V^{2}(X)\right)\right)^{T}
\end{array}\right) \times H
$$

One of the most applicable Lyapunov functions is quadratic function. Its global form is:

$$
V(X)=X^{T} P X
$$

In this equation $P$ is a positive matrix. By using the above method, if system (1) has a quadratic Lyapunov function and $\mathrm{PH}$ is positive and symmetric, its transformed system such as (2) has a quadratic Lyapunov function. Its Lyapunov function is :

$$
W(X)=\int X^{T} P H d X
$$

It can be shown that dynamical equation of almost all rotational electric machines is:

$$
\dot{X}=H^{-1}\left(A X+\left(\begin{array}{c}
X^{T} N_{1} X \\
X^{T} N_{2} X \\
\vdots \\
X^{T} N_{n} X
\end{array}\right)\right)
$$

$X, H^{-1}$ and $A$ are originated from current components, inductance, moment of inertia, and resistance of machine. Also the other states $\left(X^{T} N_{i} X\right)$ are originated from rotational voltages. This dynamic system is a transformed system therefore the above mentioned method can be used to study its stability. If a quadratic function such as (5) is found in a way that $P H$ is positive and symmetric and the following condition is satisfied:

$$
X^{T} P\left(\begin{array}{c}
X^{T} N_{1} X \\
X^{T} N_{2} X \\
\vdots \\
X^{T} N_{n} X
\end{array}\right)=0
$$

Then (6) shows its Lyapunov function.

\section{ROTOR FIELD ORIENTED VECTOR CONTROL SYSTEM}

To investigate the stability of a system, first its model must be decided. The electrical model of squirrel cage induction machine in the synchronous reference oriented to the arbitrary $\vec{\Psi}_{g}$ flux linkage vector frame is shown in (10) [17].

$$
\frac{d}{d t}\left(\begin{array}{l}
\vec{\Psi}_{S} \Psi_{g} \\
\vec{\Psi}_{r} \Psi_{g}
\end{array}\right)=\left(\begin{array}{l}
\vec{u}_{S} \Psi_{g}-r_{S} \vec{i}_{S} \Psi_{g}-j \omega_{g} \vec{\Psi}_{S} \Psi_{g} \\
-r_{S} \vec{i}_{r} \Psi_{g}-j\left(\omega_{g}-\omega_{r}\right) \vec{\Psi}_{r} \Psi_{g}
\end{array}\right)
$$

In these equations, $\vec{i}_{s} \Psi_{g}, \vec{i}_{r \Psi_{g}}, \vec{\Psi}_{s \Psi_{g}}$ and $\vec{\Psi}_{r \Psi_{g}}$ are current and flux linkage vectors of stator and rotor, respectively which can be expressed according to direct and quadrature components of stator current $\left(i_{s x}, i_{s y}\right)$ and direct and quadrature components of rotor current $\left(i_{r x}, i_{r y}\right)$.

$$
\begin{aligned}
& \vec{\Psi}_{s \Psi_{g}}=L_{s} i_{s} \Psi_{g}+L_{m} i_{r} \Psi_{g} \\
& \vec{\Psi}_{r \Psi_{g}}=L_{r} i_{r \Psi_{g}}+L_{m} i_{s} \Psi_{g} \\
& \vec{i}_{s \Psi}=i_{s x}+j i_{s y} \\
& \vec{i}_{r \Psi}=i_{r x}+j i_{r y}
\end{aligned}
$$

Also $\vec{u}_{s \Psi_{g}}$ is voltage vector of stator, $\omega_{g}$ and $\omega_{r}$ are angular speed of the frame and rotor respectively, which can be achieved by mechanical equation.

$$
J \frac{d \omega_{r}}{d t}=1.5 P L_{m}\left(\vec{i}_{r} \Psi_{g} \otimes \vec{i}_{S} \Psi_{g}\right)-B \omega_{r}-T_{L}
$$

In this equation $\otimes$ shows the vector product. Using this model, rotor field oriented vector control of induction machines can be achieved. Suppose the frame is oriented tor the rotor flux linkage so:

$$
\begin{gathered}
\Psi_{r x}=\vec{\Psi}_{r \Psi_{g}} \\
\Psi_{r y}=0 \Rightarrow i_{r y}=-\frac{L_{m}}{L_{r}} i_{s y}
\end{gathered}
$$

The electrical equation of the rotor can be decoupled to the real and imaginary parts.

$$
\begin{aligned}
& -r_{r} i_{r x}-\left(\omega_{g}-\omega_{r}\right) \Psi_{r y}+\frac{d}{d t} \Psi_{r x}=0 \\
& -r_{r} i_{r y}+\left(\omega_{g}-\omega_{r}\right) \Psi_{r x}+\frac{d}{d t} \Psi_{r y}=0
\end{aligned}
$$

Using (13), (14), (15), and (16) it can be written as: 


$$
\begin{aligned}
& -r_{r} i_{r x}+\frac{d}{d t} \Psi_{r x}=0 \\
& \left(\omega_{g}-\omega_{r}\right)=\frac{\Psi_{r x}}{r_{r} i_{r y}}
\end{aligned}
$$

The first equation shows $i_{r x}$ is affected by direct component of rotor flux linkage, therefore when its variation is slow or even it is constant in the steady state, $i_{r x}$ becomes zero. As a result the motor torque can be written as:

$$
\begin{gathered}
T_{e}=1.5 P L_{m}\left(\vec{i}_{s} \otimes \vec{i}_{r}\right) \\
\Psi_{r x}=\vec{\Psi}_{r \Psi_{r}}=L_{m} i_{s x}
\end{gathered}
$$

Equation (20) shows that rotor flux can be controlled by direct component of stator current and therefore from (19) the torque can be controlled by quadrature component of stator current. As a result the goal of the vector control is satisfied.

To implement this control two problems remain. The first one is that the rotor flux linkage vector must be tracked. To do this, (18) can be used to produce:

$$
\rho_{r}=\int \omega_{g} d t=\int\left(\omega_{r}+\frac{i_{s x}}{\tau_{r} i_{s y}}\right) d t
$$

The second one is that the direct and quadrature current components must be produced. If the voltage source inverter is used to produce these components, a control strategy will be needed to produce them. To do this, each component of stator voltages such as $u_{s x}$ is divided into two components $\left(u_{s x}=u_{x}+u_{d x}\right)$. One of these components $\left(u_{x}\right)$ is used to control the same current component $\left(i_{s x}\right)$ and the other is supplied to control the other component $\left(i_{s y}\right)$ :

$$
\begin{gathered}
u_{s x}=u_{x}+u_{d x}=r_{s} i_{s x}+\frac{d}{d t} \Psi_{s x}-\omega_{g} \Psi_{s y} \\
u_{s y}=u_{y}+u_{d y}=r_{s} i_{s y}+\frac{d}{d t} \Psi_{s y}+\omega_{g} \Psi_{s x} \\
u_{d x}=-\omega_{g} \Psi_{s y}=-\omega_{g} L_{s}^{\prime} i_{s y} \\
u_{d y}=\omega_{g} \Psi_{s x}=\omega_{g} L_{s} i_{s x}
\end{gathered}
$$

In these equations $L_{s}^{\prime}=\left(L_{s}-\frac{L_{m}^{2}}{L_{r}}\right)$ is the stator transient inductance. By using reference values of current instead of their actual values, the voltage references for inverter are achieved. Flux linkage is controlled by reference direct current component, but reference quadrature current component is adjusted to control the speed because this component controls torque. Therefore reference current components are defined as:

$$
i_{\text {sxref }}=\frac{\Psi_{\text {ref }}}{L_{m}}
$$

$$
i_{\text {syref }}=k_{p \omega}\left(\omega_{r e f}-\omega_{r}\right)+k_{i \omega} \int\left(\omega_{r e f}-\omega_{r}\right) d t
$$

A rotor flux oriented vector control model can be written according to the above discussion.

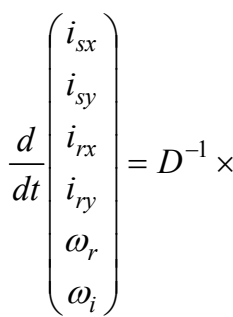

$$
\times\left(\begin{array}{c}
r_{s} i_{\text {sxref }}-M L_{s} i_{\text {syref }}-r_{s} i_{s x}+M\left(L_{s} i_{s y}+L_{m} i_{r y}\right) \\
-r_{s} i_{\text {syref }}-M L_{s} i_{\text {sxref }}-r_{s} i_{s y}-M\left(L_{s} i_{s x}+L_{m} i_{r x}\right) \\
-r_{r} i_{r x}+\frac{i_{\text {syref }}}{\tau_{r} i_{\text {sxref }}}\left(L_{m} i_{s y}+L_{r} i_{r y}\right) \\
-r_{r} i_{r y}-\frac{i_{\text {syref }}}{\tau_{r} i_{s x r e f}}\left(L_{m} i_{s x}+L_{r} i_{r x}\right) \\
\frac{1}{J}\left(1.5 P L_{m}\left(i_{s y} i_{r x}-i_{s x} i_{r y}\right)-B \omega_{r}-T_{L}\right) \\
\omega_{r e f}-\omega_{r}
\end{array}\right)
$$

In these equations $M=\left(\omega_{r}+\frac{i_{\text {syref }}}{\tau_{r} i_{\text {sxref }}}\right)$ and $D^{-1}$ is :

$$
D^{-1}=\frac{1}{L_{L}}\left(\begin{array}{cccccc}
L_{r} & 0 & -L_{m} & 0 & 0 & 0 \\
0 & L_{r} & 0 & -L_{m} & 0 & 0 \\
-L_{m} & 0 & L_{s} & 0 & 0 & 0 \\
0 & -L_{m} & 0 & L_{s} & 0 & 0 \\
0 & 0 & 0 & 0 & L_{L} & 0 \\
0 & 0 & 0 & 0 & 0 & L_{L}
\end{array}\right)
$$

Figure (1) depicts a rotor field oriented vector control drive.

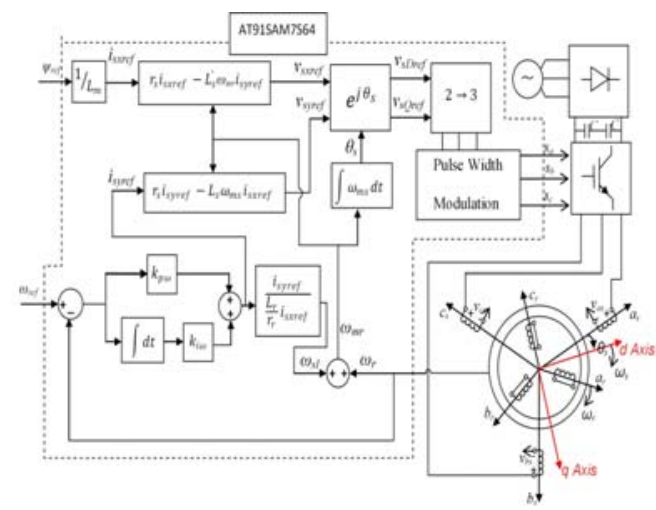

Fig. 1. Rotor field oriented vector control drive. 


\section{STABILITY ANALYSIS OF THE SYSTEM}

To study the stability analysis of a rotor field oriented vector control at first the equilibrium point of (28) must be obtained. The zero state of the dynamical equation of the system must be transformed to the origin. When the speed controller is only proportional controller, the equilibrium point of this system is [14]:

$$
\begin{gathered}
i_{s x}^{*}=i_{\text {sxref }}, i_{r x}^{*}=0, i_{s y}^{*}=-\frac{L_{r}}{L_{m}} i_{r y}^{*}, i_{r y}^{*}=-\frac{T_{L}+B \omega_{r}^{*}}{1.5 P L_{m} i_{s x r e f}} \\
\omega_{r}^{*}=\frac{\left(\frac{1.5 P L_{m}^{2} i_{s x r e f} k_{p \omega}}{L_{r}}\right) \omega_{r e f}-T_{L}}{B+\frac{1.5 P L_{m}^{2} i_{s x r e f} k_{p \omega}}{L_{r}}}
\end{gathered}
$$

But when the speed controller is proportional-integral, the equilibrium is [14]:

$$
\begin{gathered}
i_{s x}^{*}=i_{s x r e f}, i_{r x}^{*}=0, i_{s y}^{*}=-\frac{L_{r}}{L_{m}} i_{r y}^{*}, i_{r y}^{*}=-\frac{T_{L}+B \omega_{r}^{*}}{1.5 P L_{m} i_{s x r e f}} \\
\omega_{r}^{*}=\omega_{r e f}, \omega_{i}^{*}=\frac{i_{s y}^{*}}{k_{i \omega}}
\end{gathered}
$$

For simplicity the proportional speed controller is considered. The new variables for the new system are chosen as:

$$
\begin{gathered}
x_{1}=i_{s x}-i_{s x}^{*}, x_{2}=i_{s y}-i_{s y}^{*}, x_{3}=i_{r x}-i_{r x}^{*} \\
x_{4}=i_{r y}-i_{r y}^{*}, x_{5}=\omega_{r}-\omega_{r}^{*}
\end{gathered}
$$

Therefore dynamical equations of the new system are:

$$
\begin{aligned}
& \frac{d}{d t}\left(\begin{array}{c}
x_{1} \\
x_{2} \\
x_{3} \\
x_{4}
\end{array}\right)=L^{-1}\left(\begin{array}{c}
S L_{s} k_{p \omega} x_{5}-r_{s} x_{1}+S\left(L_{s} x_{2}+L_{m} x_{4}\right) \\
-r_{s} k_{p \omega} x_{5}-r_{s} x_{2}-S\left(L_{s} x_{1}+L_{m} x_{3}\right) \\
-r_{r} x_{3}+T\left(L_{r} x_{4}+L_{m} x_{2}\right)+\frac{k_{p \omega} L_{m}}{\tau_{r}} x_{5} \\
-r_{r} x_{4}-T\left(L_{r} x_{3}+L_{m} x_{1}\right)^{r}
\end{array}\right) \\
& \frac{d x_{5}}{d t}=\frac{1}{J}\left(T_{T e}-B x_{5}\right) \\
& T_{T e}=1.5 P L_{m}\left(x_{3}\left(x_{2}+i_{s y}^{*}\right)-x_{1} x_{4}-x_{1} i_{r y}^{*}-x_{4} i_{s x r e f}\right) \\
& S=\frac{k_{p \omega}\left(\omega_{r e f}-\left(x_{5}+\omega_{r}^{*}\right)\right)}{\tau_{r} i_{\text {sxref }}}+\left(x_{5}+\omega_{r}^{*}\right) \\
& T=\frac{k_{p \omega}\left(\omega_{r e f}-\left(x_{5}+\omega_{r}^{*}\right)\right)}{\tau_{r} i_{\text {sxref }}}
\end{aligned}
$$

$L$ is machine inductances given bellow:

$$
L=\left(\begin{array}{cccc}
L_{s} & 0 & L_{m} & 0 \\
0 & L_{s} & 0 & L_{m} \\
L_{m} & 0 & L_{r} & 0 \\
0 & L_{m} & 0 & L_{r}
\end{array}\right)
$$

This system's equation is similar to equation (7). In this equation $H$ and $N_{i}$ are given below:

$$
H=\left(\begin{array}{cc}
L & 0 \\
0 & \frac{1}{J}
\end{array}\right)
$$

$$
N_{1}=\left(\begin{array}{ccccc}
0 & 0 & 0 & 0 & 0 \\
0 & 0 & 0 & 0 & \frac{M L_{s}}{2} \\
0 & 0 & 0 & 0 & 0 \\
0 & 0 & 0 & 0 & \frac{M L_{m}}{2} \\
0 & \frac{M L_{s}}{2} & 0 & \frac{M L_{m}}{2} & 0
\end{array}\right)
$$

$$
N_{2}=\left(\begin{array}{ccccc}
0 & 0 & 0 & 0 & 0 \\
0 & 0 & 0 & 0 & -\frac{M L_{s}}{2} \\
0 & 0 & 0 & 0 & 0 \\
0 & 0 & 0 & 0 & -\frac{M L_{m}}{2} \\
0 & -\frac{M L_{s}}{2} & 0 & -\frac{M L_{m}}{2} & 0
\end{array}\right)
$$

$$
N_{3}=\left(\begin{array}{ccccc}
0 & 0 & 0 & 0 & 0 \\
0 & 0 & 0 & 0 & -\frac{M L_{s}}{2} \\
0 & 0 & 0 & 0 & 0 \\
0 & 0 & 0 & 0 & -\frac{M L_{m}}{2} \\
0 & -\frac{M L_{s}}{2} & 0 & -\frac{M L_{m}}{2} & 0
\end{array}\right)
$$

$$
N_{4}=\left(\begin{array}{ccccc}
0 & 0 & 0 & 0 & 0 \\
0 & 0 & 0 & 0 & \frac{M L_{s}}{2} \\
0 & 0 & 0 & 0 & 0 \\
0 & 0 & 0 & 0 & \frac{M L_{m}}{2} \\
0 & \frac{M L_{s}}{2} & 0 & \frac{M L_{m}}{2} & 0
\end{array}\right)
$$

$N_{5}=\left(\begin{array}{ccccc}0 & 0 & 0 & -\frac{3 P L_{m}}{2 J} & 0 \\ 0 & 0 & -\frac{3 P L_{m}}{2 J} & 0 & 0 \\ 0 & -\frac{3 P L_{m}}{2 J} & 0 & 0 & 0 \\ -\frac{3 P L_{m}}{2 J} & 0 & 0 & 0 & 0 \\ 0 & 0 & 0 & 0 & 0\end{array}\right)$ 


$$
\begin{gathered}
M=\left(1-\frac{k_{p \omega}}{\tau_{r} i_{\text {sxref }}}\right) \\
N=\frac{k_{p \omega}}{\tau_{r} i_{\text {sxref }}}
\end{gathered}
$$

According to (7) matrix $P$ can be:

$$
P=\left(\begin{array}{ccccc}
1 & 0 & 0 & 0 & 0 \\
0 & 1 & 0 & 0 & 0 \\
0 & 0 & 1 & 0 & 0 \\
0 & 0 & 0 & 1 & 0 \\
0 & 0 & 0 & 0 & \frac{2 J}{3 P}
\end{array}\right)
$$

This matrix satisfies the conditions mentioned in section2. The Lyapunov function of the system is obtained according to (7):

$$
\begin{gathered}
W^{2}(X)=L_{s} x_{1}^{2}+L_{s} x_{2}^{2}+L_{r} x_{3}^{2}+L_{r} x_{4}^{2}+ \\
+2 L_{m} x_{1} x_{3}+2 L_{m} x_{1} x_{3}+\frac{2 J}{3 P} x_{5}^{2}
\end{gathered}
$$

Boundary of different parameters such as speed controllers values, the reference speed, or flux values to have stable response can be achieved using this Lyapunov function. To do this time derivation of this function must be negative.

\section{EXPERIMENTAL APPROACH}

An experimental prototype was prepared by the authors to verify the analysis. A laboratory $175 \mathrm{~W}$ and four pole three phase induction motor whose parameters and characteristics are shown in Table I is used. AT91SAM7S64 microcontroller is used to implement the rotor speed calculation and filtering, speed controller, and processing operation including the calculation of reference voltage values for inverter, pulsewidth-modulation (PWM), DC bus voltage control, reference values setting such as reference speed and reference flux linkage, etc.

TABLE I. INDUCTION MOTOR PARAMETERS

\begin{tabular}{|c|c|c|}
\hline Parameter & Description & Value \\
\hline $\mathrm{r}_{\mathrm{s}}$ & stator resistor & $43.1 \Omega$ \\
\hline $\mathrm{r}_{\mathrm{r}}$ & rotor resistor & $72 \Omega$ \\
\hline $\mathrm{L}_{\mathrm{s}}$ & stator inductance & $1.995 \mathrm{H}$ \\
\hline $\mathrm{L}_{\mathrm{r}}$ & rotor inductance & $1.995 \mathrm{H}$ \\
\hline $\mathrm{L}_{\mathrm{m}}$ & Mag. inductance & $1.96 \mathrm{H}$ \\
\hline $\mathrm{J}$ & moment of inertia & $0.0024 \mathrm{Kgm}$ \\
\hline $\mathrm{B}$ & friction coefficient & $0.001 \mathrm{Kgm} / \mathrm{s}$ \\
\hline $\mathrm{T}_{\mathrm{L}}$ & no-load torque & $0.1 \mathrm{Nm}$ \\
\hline
\end{tabular}

This microcontroller can work with $55 \mathrm{MHz}$ clock signal but it was used with $48 \mathrm{MHz}$ clock and has ARM core therefore it can be used for this drive which needs high speed processing operation. To measure the speed of the rotor a 2000- pulse/revolution speed encoder is connected to the shaft of rotor. Its pulses after a voltage level adjusting are used for counter of the microcontroller. Microcontroller gives the actual speed by calculating the speed and filtering it by an FIR filtering and a low-pass filter to neutralize the quantization error and noise. A logic operation board is designed to operate on PWM pulses produced by microcontroller. These pulses after high-speed optocouplers are delivered to the power section. An Inverter with IGBT switches, RC snubber circuit, and high-speed anti-parallel power diodes is designed to supply the motor.

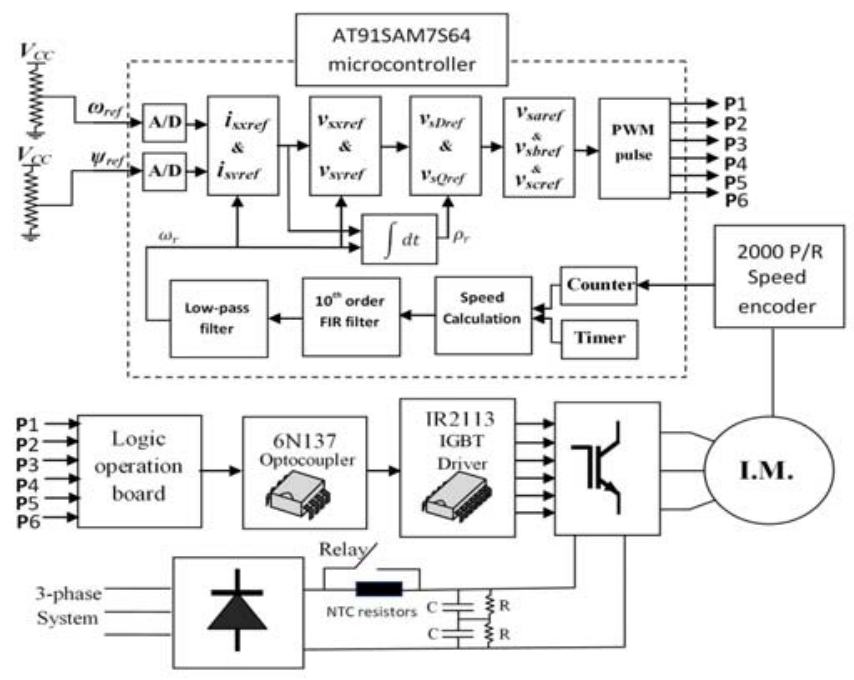

Fig. 2. Experimental set-up diagram.
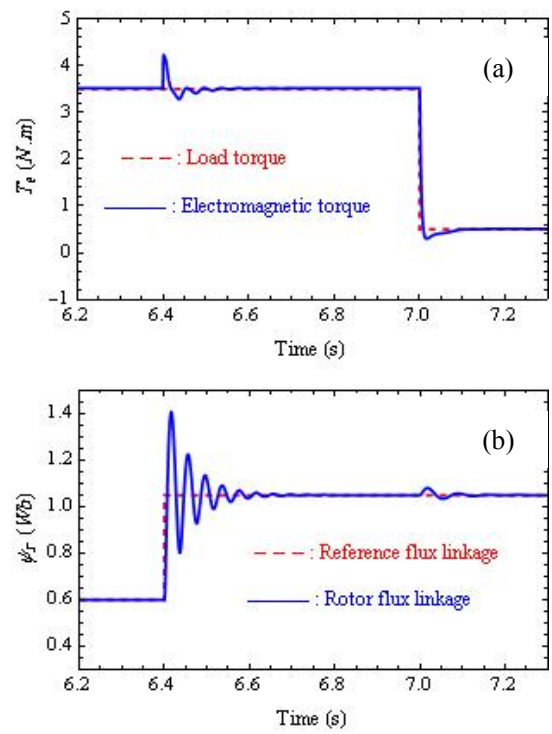

Fig. 3. Vector control response: (a) Flux linkage response, (b) Torque response

PWM pulses are delivered to IGBT driver circuits to turn the IGBT switches on or off. Also a 530-volt DC bus voltage is designed using three phase voltages, rectifiers, NTC resistors, relay, capacitors, discharge circuit, etc. The output current is 
monitored using a shunt resistor and a digital oscilloscope. Figure (2) shows the block diagram of experimental setup. Figure (3) shows dynamical response of the system depicted in Figure (1). As illustrated in Figure (3a) when the value of flux reference is changed, electromagnetic torque of the motor does not affected. Also, as seen in Figure (3b) when the Load torque is changed, the value of flux fluctuates negligibly.

TABLE II. EQUILIBRIUM POINTS FOR THREE SET POINTS

\begin{tabular}{|c|c|c|c|c|c|c|c|c|}
\hline CASE & $\omega_{r e f}$ & $\psi_{r e f}$ & $k_{p \omega}$ & $i_{s y}^{*}$ & $i_{r x}^{*}$ & $i_{r y}^{*}$ & $\omega_{r}^{*}$ & $\omega_{i}^{*}$ \\
\hline 1 & 230 & 0.95 & 2 & 0.48 & 0.11 & -0.11 & 230 & 1.18 \\
\hline 2 & 230 & 0.1 & 5 & 0.05 & 1.12 & -1.12 & 230 & 1.12 \\
\hline 3 & 130 & 0.95 & 2 & 0.48 & 0.08 & -0.08 & 130 & 0.82 \\
\hline
\end{tabular}

Table II shows three set point and speed controller values for rotor field oriented vector control drive and also their equilibrium states calculated by (30). Figures (4a) and (4b) illustrates dynamical responses of the system by changing the set points from case 1 to case 2 at $\mathrm{t}=6.98 \mathrm{sec}$. As shown in these figures, the system response is stable in case 1 and is unstable in case 2 . These results are shown in [14] that the case 2 has a chaotic response. Figure (5) portrays the Lyapunov time derivative for two cases. As shown in case 1, time derivation of the Lyapunov function becomes negative and remains until zero which shows that this set point is stable. When the set point changes to case 2, time derivative of Lyapunov function becomes positive and negative alternatively which shows that the system response converges to the equilibrium point and then diverges from it.
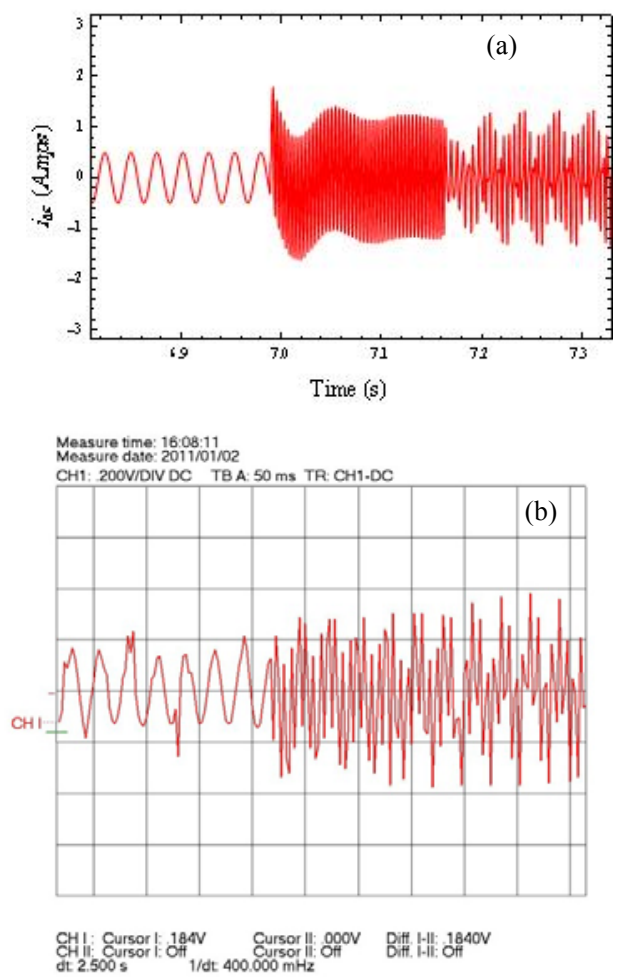

Fig. 4. Current responses of cases 1 and 2: (a) simulation, (b) experimental

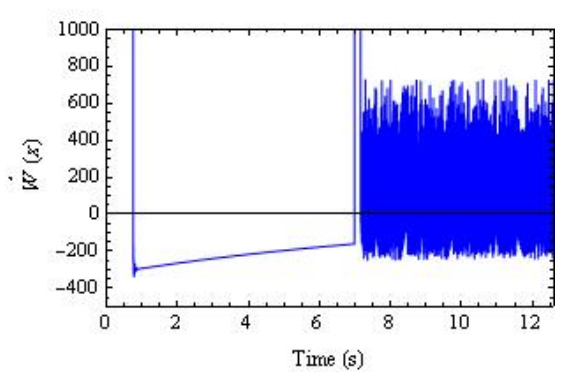

Fig. 5. Derivation value of Lyapunov function for cases 1 and 2.

It is clear that there is a stable region in the phase plane. It is obtained numerically for both cases. $\dot{W}(X)$ for $\omega_{\text {ref }}=230 \mathrm{rad} / \mathrm{s}, \Psi_{r e f}=0.95 \mathrm{~Wb}, k_{p \omega}=2$ and $k_{i \omega}=0.1$ is:

$$
\begin{gathered}
\dot{W}(X)=-20.93 x_{1}^{2}-20.93 x_{2}^{2}-20.93 x_{3}^{2}-20.93 x_{4}^{2} \\
-0.06 x_{5}+0.04 x_{3} x_{5}+40.63 x_{4} x_{5}-0.000067 x_{5}^{2} \\
-63.41 x_{2}+41.59 x_{2} x_{5}-124.804 x_{2} x_{3}+0.48 x_{2} x_{3} x_{5} \\
-2.09 x_{2} x_{6}-2.06 x_{4} x_{6}-x_{5} x_{6}-9.95 x_{1}+124.8 x_{1} x_{4} \\
-0.09 x_{1} x_{5}-0.048 x_{1} x_{4} x_{5}+0.007 x_{1} x_{6}
\end{gathered}
$$

Figures (6) shows the area in which the $\dot{W}(X)$ is negative for case 1 and 2, respectively. For these cases the other three states vary between -0.1 and 0.1 . According to the Lyapunov theorem the case 1 is stable and the case 2 is not stable because in case 1 there is an area around the origin in which $\dot{W}(X)$ is negative. But in case 2 there is not such an area around the origin, so it is not stable. The phase plane trajectories for these cases are also shown in these figures. Note that these trajectories do not intersect with each other in the space.
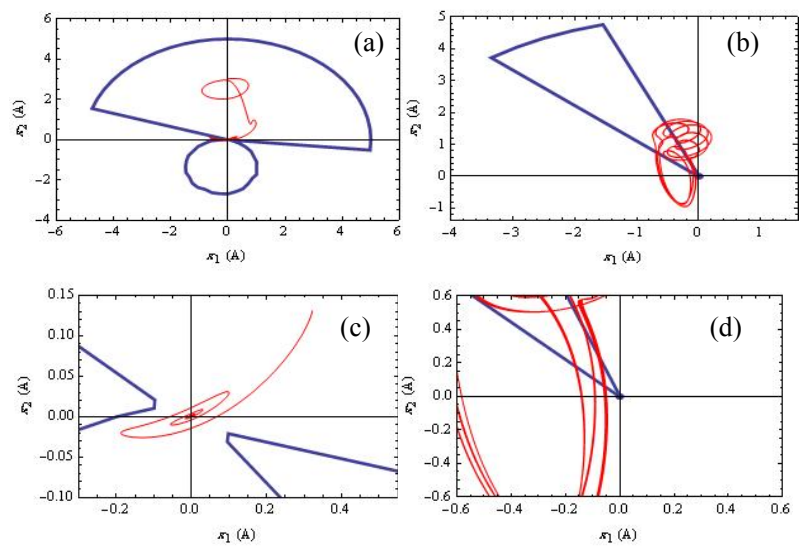

Fig. 6. Area of negative Lyapunov time derivative. (a) stable area for case 1. (b) stable area for case 2. (c) stable area for case 1 (magnified). (d) stable area for case 2 (magnified).

As discussed above, the trajectories of the system cannot settle down to the origin in case 2 because the derivation of Lyapunov function is not negative even in a small area around 
the origin. Generally speaking, this fact can be used to determine whether or not a case has a stable condition. As an example, consider the following case (case 3). Figure (7) shows the area in which time derivative of Lyapunov function is negative. As it is obvious there is an area around the origin in which the time derivative of Lyapunov function is negative. Therefore this case is a stable case. Figures (8a) and (8b) illustrate the simulated and experimental response of the drive for case 3, respectively. The state space trajectory is given in Figure (7).
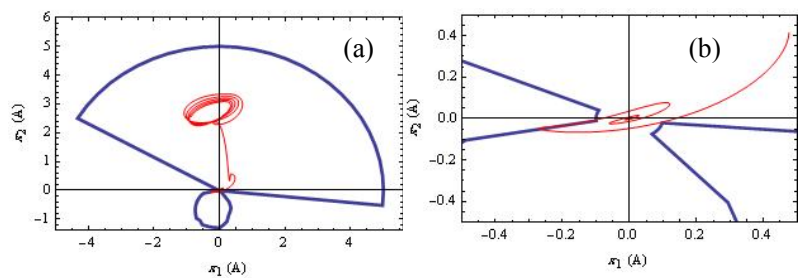

Fig. 7. Stable areas for case 3: (a) stable area for case 3, (b) stable area for case 3 (magnified).
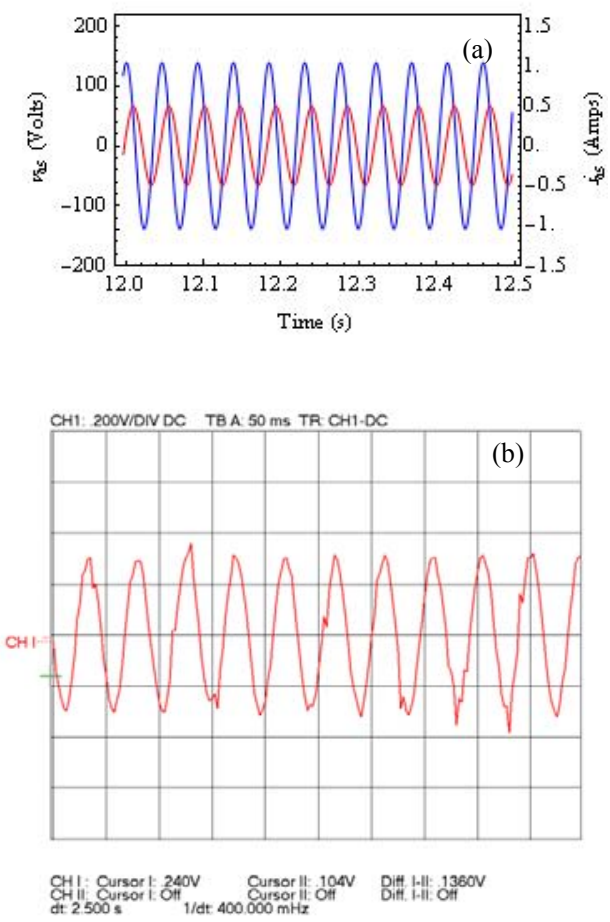

Fig. 8. Current responses for case 3: (a) simulation (b) experimental

This method can be used to find the range of speed controller's gain values, reference flux, reference speed, etc. for stable responses. The Figure (9a) and (9c) illustrate the area in which time derivative of the Lyapunov function is negative for different speed proportional controller gains. As shown, there is a range of this parameter which makes the system to be stable. Also Figure (9b) and (9d) show the areas for different reference flux linkages. Also in these cases there is a range of flux linkages which makes the system stable.
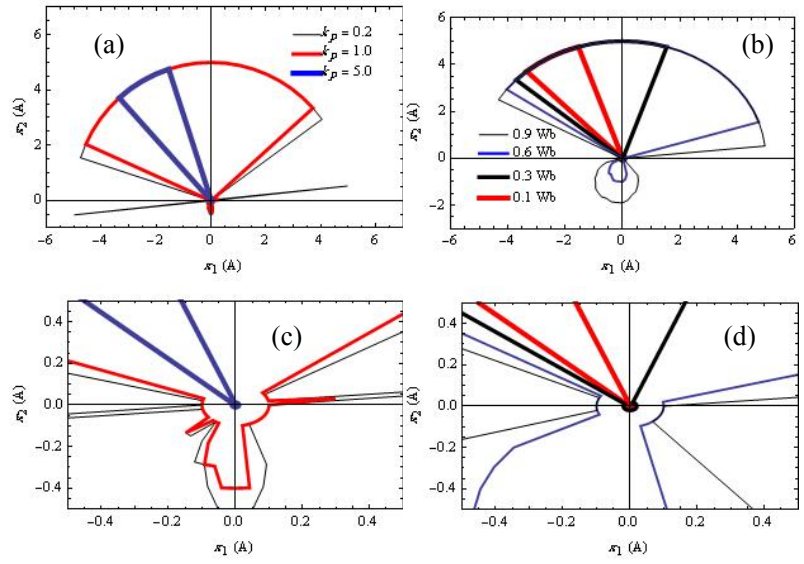

Fig. 9. Area of negative Lyapunov derivation for different parameters. (a) different $k_{p \omega}$ (b) different $\psi_{r e f}$ (c) different $k_{p \omega}$ (magnified) (d) different $\psi_{r e f}$ (magnified).

\section{CONCLUSION}

In this paper a useful Lyapunov function is achieved for vector control drives of induction machines. Stable range of set points such as reference flux linkage, speed or other parameters of the system can be investigated using this function. By obtaining this stable condition for each drive, they can be set offline to avoid unstable response or chaotic behavior.

\section{ACKNOWLEDGMENT}

This paper is result of a research sponsored by Firoozkooh Branch, Islamic Azad University, Firoozkooh, Iran.

\section{REFERENCES}

[1] Z. Park, J. B. Park, Y. H. Joo, B. Zhang, G. Chen, "Bifurcation and chaos in a permanent magnet synchronous motor", IEEE Transaction on Circuits-I, Vol. 49, pp. 383-387, 2002

[2] D. Q. Wei, X. S. Luo, B. H. Wang, J. Q. Fang, "Robust adaptive dynamic surface control of chaos in permanent magnet synchronous motor", Phys. Letter A, Vol. 363, pp. 71-77, 2007

[3] M. Babaei, J. Nazarzadeh, J. Faiz, "Nonlinear feedback control of chaos in synchronous reluctance motor drive systems", IEEE International Conference on Industrial Technology (ICIT 2008), pp. 1-5, China, 2008

[4] Y. Gao, K. T. Chau, "Hopf Bifurcation and Chaos in Synchronous Reluctance Motor Drives", IEEE TRNSACTION On ENERGY CONVER, Vol. 19, pp. 296-302, 2004

[5] J H Chen, K T Chau, C C Chan, Q Jiang, "Subharmonics and Chaos in Switched Reluctance Motor Drives", Ieee Transaction on Energy Convertion, Vol. 17, pp. 73-78, 2002

[6] H. Ren, D. Liu, "Nonlinear Feedback Control of Chaos in Permanent Magnet Synchronous Motor", IEEE Transaction on Circuits-II Vol. 53, pp. 45-50, 2006

[7] T Tang, M Yang, H Li, D Shen, "A New Discovery and Analysis on Chaos and Bifurcation in DC Motor Drive System with Full-bridge Converter", 1ST IEEE Conference on Industrial Electronics and Applications, pp. 1-6, Singapore, 2006

[8] I. Nagy, "Tolerance band based current control of induction machines highlighted with the theory of chaos", 3rd IEEE International Power Electronics Congress, CIEP '94, pp. 155-160, Mexico, 1994

[9] Z. Suto, I. Nagy, E. Masada, "Avoiding chaotic processes in current control of AC drive", 29th Annual IEEE Power Electronics Specialists Conference, PESC 98, pp. 255-261, Japan,1998 
[10] T. Asakura, K. Yoneda, Y. Saito, M. Shioya, "Chaos detection in velocity control of induction motor and its control by using neural network", 5th IEEE International Conference on Signal Processing Proceedings; pp. 1633-1638, China, 2000

[11] T. Asakura, Y. Saito, M. Shioya, "Chaos detection and neuro-control in vector control system", IEEE Region 10 Conference on Computers, Communications, Control and Power Engineering, pp. 1347-1350, China, 2002

[12] F. Salas, R. Ortega, J. Aracil, "Hopf bifurcation in indirect field-oriented control of induction motors", Automatica, Vol. 38, pp. 829-835, 2002

[13] A. B. Ozer, E. Akin, "Chaos Control in Vector-controlled Induction Motor Drive", Electric Power Components and Systems, Vol. 36, pp. 733-740, 2008

[14] R. A. Sangrody, J. Nazarzadeh, K. Y. Nikravesh, "Inherent Chaotic Behavior in Vector Control Drives of Induction Machines", Electric Power Components and Systems, Vol. 40, pp.1-20, 2012

[15] H. Zhang, X. Ma, B. Xue, W. Liu, "Study of intermittent bifurcations and chaos in boost PFC converters by nonlinear discrete models", Chaos Soliton Fractal, Vol. 23, pp. 431-444, 2005

[16] K. Y. Nikranesh, Nonlinear system stability analysis Lyapunov-based approach, USA: CRC Press, pp. 106-111, 2013

[17] P. Vas, Sensorless Vector and direct torque control, UK: Oxford University Press, 1998

\section{AUTHORS PROFILE}

Reza Sangrody was born in Babol, Iran in 1981. He received his BSc and MSc degree in power electrical engineering from Mazandaran University in 2003 and 2005, respectively. He received his $\mathrm{PhD}$ degree in power electrical engineering from Islamic Azad University, Science and Research branch in 2012. At present his interest areas include nonlinear dynamical systems, power electronic applications and control of electrical drives. Mr. Sangrody joined Islamic Azad University, Firoozkooh branch in 2006 as faculty member.

Seyed Mohammad Shariatmadar was born in Qom, Iran, in August 1973. He received the B.Sc. degree from Tehran University, Tehran, Iran, in 1996, the M.Sc. degree from the South Tehran Branch, Azad University, in 2003 and the Ph.D. degree in electrical engineering at the Science and Research Branch, Islamic Azad University Tehran, Iran in 2011. His current research interests include modeling, analysis, and control of electrical machines, power electronic drives and nonlinear phenomena in power electronics systems 